\title{
Iniciativas Desenvolvidas Junto do Presidente da FCT
}

Na sequência de recentes alterações legislativas que têm influência directa na vida das Universidades, dos Laboratórios de Investigação e de Escolas Secundárias e ainda para tratar de assuntos de interesse para a SPQ, nomeadamente os relativos às efemérides em que a SPQ estará directamente envolvida: o Ano internacional da Química e Centenário da SPQ, houve uma reunião da Direcção da SPQ com o Presidente da Fundação para a Ciência e a Tecnologia, Prof. João Sentieiro, no passado dia 13 de Abril.Dessa reunião resultou, em particular, que:i) O carácter extraordinário das celebrações de 2011 será reconhecido pela FCT, que deverá conceder um apoio específico - naturalmente para além do que poderá ser concedido através dos programas normais (FACC, etc). O compromisso de apoio poderá ser assumido pelo actual presidente antes do fim da legislatura. Para se concretizar tal apoio, a SPQ deverá preparar até Setembro um programa de actividades provisório, mas já com alguma estrutura definida, eventos principais, e estimativa de custos, a ser entregue ao presidente da FCT numa audiência pedida para o efeito.ii) Relativamente às questões da legislação, o presidente da FCT demonstrou abertura para as abordar com o ministro da tutela, devendo no entanto ser-Ihe fornecidos os elementos que evidenciem os problemas específicos. Neste sentido, reproduzimos abaixo o teor de duas cartas dirigidas pelo Secretário-Geral da SPQ ao Prof. João Sentieiro. É importante que, nesta fase, as Universidades, Laboratórios, Grupos de Investigação e Escolas Secundárias, façam sentir à tutela as restrições que estão a ser impostas pela legislação e que limitam o normal desenvolvimento das actividades de ensino, investigação e desenvolvimento. No limite, poderá estar em causa a capacidade de execução de programas e projectos geradores de receita própria das Universidades e Laboratórios.

Jorge Morgado
Ex. ${ }^{\text {mo }}$ Senhor

Prof. Doutor João Sentieiro

Presidente da Fundação para a Ciência e a Tecnologia

Assunto: Novas regras para a Aquisição de Bens e Serviços e o funcionamento normal de laboratórios de investigação e ensino.

27.Abril.2009

A Sociedade Portuguesa de Química (SPQ) foi alertada para o facto de as novas regras para Aquisição de Bens e Serviços - que obrigam a concursos públicos para aquisição de serviços e de compostos químicos - constituírem um entrave muito significativo ao normal desenvolvimento das actividades de investigação científica em Portugal, limitando inexoravelmente a competitividade, e inovação e a capacidade de resposta dos cientistas que desenvolvem a sua actividade nas instituições portuguesas.

Deste modo, a SPQ solicita o reconhecimento da especificidade da investigação científica, e propõe a criação de um regime próprio que contemple a imprevisibilidade de uma parcela das aquisições efectuadas.

O Decreto-Lei n. ${ }^{\circ} 18 / 2008$, de 29 de Janeiro, que aprova o Código dos Contratos Públicos, e regula aquisição de bens móveis e de aquisição de serviços, está a ser interpretado pelas entidades responsáveis como limitando ao valor máximo de 75.000 euros em 3 anos a aquisição de compostos químicos e pequeno material de laboratório por ajuste directo, implicando o recurso a concurso público para aquisições de montantes superiores. O mesmo se aplica a aquisição de serviços o que inclui a reparação de equipamentos, por exemplo.

Esta limitação é particularmente gravosa para a actividade de investigação científica em Laboratórios de Química (e em todos os que dependem da aquisição de compostos químicos), porquanto as aquisições anuais aos mais importantes fornecedores ultrapassam largamente este valor e a actividade de investigação científica é incompatível com a previsibilidade das aquisições assumida pelo legislador.

De facto, as informações recolhidas pela SPQ junto das instituições universitárias e laboratórios de investigação mostram que:

1) As aquisições por ajuste directo aos maiores fornecedores de compostos químicos especializados (de que é exemplo a empresa Sigma-Aldrich) por instituições universitárias ultrapassam o valor limite de 75000 euros em apenas 6 a 7 meses.

O concurso público torna-se, assim, inevitável para a aquisição da larga maioria dos reagentes necessários durante 3 anos (de facto, neste momento, já todas as instituições contactadas ultrapassaram o limite para aquisições por ajuste directo).

2) O grau de sobreposição entre as listas de produtos químicos adquiridos em 2007 e 2008 é inferior a $40 \%$ na maioria dos laboratórios de investigação.Isto significa que é possível prever - e sujeitar a concurso público - uma fracção considerável das aquisições, mas é virtualmente impossível prever a totalidade das necessidades com a antecedência necessária ao processo de concurso público.

Resulta daqui que sempre que um investigador pretenda adquirir um composto que não está previsto em nenhum concurso já realizado - em resultado da imprevisibilidade da sua actividade, como descobertas recentes, solicitações externas, aprovação de projectos, ou outras - terá de aguardar pela realização de um novo concurso.

O mesmose passa com a reparação de equipamentos. Esta situação resulta num estrangulamento da actividade, que efectivamente penaliza a investigação realizada em território nacional. 
É entendimento da SPQ que o problema pode ser facilmente ultrapassado reconhecendo a especificidade da actividade de investigação científica, com a criação de um regime que alargue o limite máximo concedido para ajuste directo a valores compatíveis com o normal desenvolvimento da Ciência em Portugal.

Esperando que este problema seja merecedor da atenção de V. Ex. ${ }^{a}$, a Sociedade Portuguesa de Química fica ao dispor para contribuir para a solução do mesmo.

Com os meus melhores cumprimentos,

Paulo Ribeiro Claro

Secretário-Geral da SPQ

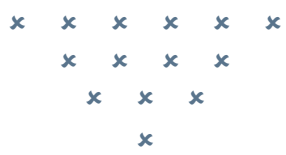

Ex. ${ }^{\text {mo }}$ Senhor

Prof. Doutor João Sentieiro

Presidente da Fundação para a Ciência e a Tecnologia

Assunto: Actual legislação sobre estupefacientes e substâncias psicotrópicase o funcionamento normal de laboratórios de investigação e ensino.

A Sociedade Portuguesa de Química (SPQ) foi alertada para o facto de a actual legislação sobre estupefacientes e substâncias psicotrópicas (DL15/93) poder penalizar a utilização de alguns compostos químicos de uso vulgar em laboratórios de investigação e de aulas. De facto, verifica-se que a aplicação cega desta legislação poderá colocar na situação de ilegalidade todas as instituições de ensino e investigação com laboratórios de química - o que inclui todos os departamentos de química universitários e inúmeras escolas secundárias.

No sentido de compatibilizar o normal funcionamento destes laboratórios com o cumprimento da Lei, a SPQ vem propor a definição de um regime de excepção, análogo ao utilizado na legislação relativa a Armas Químicas.
O Decreto-Lei n¹5/93 de 22 de Janeiro tem por objecto (tal como referido no seu Artigo $1^{\circ}$ ) a definição do regime jurídico aplicável ao tráfico e consumo de estupefacientes e substâncias psicotrópicas. No preâmbulo, o legislador define três objectivos fundamentais, dos quais se transcreve o segundo pela relevância que tem para o assunto em análise: "Em segundo lugar, adoptar medidas adequadas ao controlo e fiscalização dos precursores, produtos químicos e solventes, substâncias utilizáveis no fabrico de estupefacientes e de psicotrópicos e que pela facilidade de obtenção e disponibilidade no mercado corrente, têm conduzido ao aumento do fabrico clandestino de estupefacientes e substâncias psicotrópicas." No número 2 do Artigo $22^{\circ}$ referente a precursores o referido Decreto-lei determina que "2- Quem, sem se encontrar autorizado, detiver, a qualquer título, equipamento, materiais ou substâncias inscritas nas tabelas $V$ e VI, sabendo que são ou vão ser utilizados no cultivo, produção ou fabrico ilícitos de estupefacientes ou substâncias psicotrópicas, é punido com pena de prisão de um a cinco anos". Se repararmos que na Tabela VI estão referidas substâncias que são solventes/reagentes comuns em qualquer laboratório de investigação/ demonstração ou mesmo em laboratórios de escolas, como porexemplo a acetona, o tolueno, o permanganato de potássio, o ácido clorídrico ou o éter etílico, constata-se que a quantidade de pessoas ou instituições em possível transgressão é enorme. É verdade que o mesmo Decreto-Lei prevê, no número dois do Artigo $4^{\circ}$, a possibilidade de pedir à Direcção Geral do Comércio Externo a autorização para importação ou exportação dos referidos produtos, e no número 7 do mesmo Artigo o licenciamento de instalações onde se fabriquem os produtos, mas nada prevê para a detenção dos referidos compostos em laboratórios de investigação/demonstração.

Pode argumentar-se que o número 2 do Artigo $22^{\circ}$ diz que, para que seja considerada a prevaricação é necessário "saber que os referidos produtos são ou vão ser utilizados com fins ilícitos", mas tal parece não ser justificação suficiente: de facto, é do conhecimento público pelo menos um caso de intervenção da Autoridade de Segurança Alimentar e Económica (ASAE) em laboratórios universitários, com ameaça de encerramento dos mesmos, fundamentada nesta legislação.

Neste sentido, seria fundamental e da máxima urgência que fosse efectuado um aditamento ao referido Decreto-Lei que previsse os laboratórios de investigação/demonstração e os laboratórios escolares como casos de excepção, eventualmente fixando os montantes máximos que seria possível deter sem violar a lei. Tal tem sido a prática usual. Por exemplo, na Lei n66/2007 de 28 de Novembro sobre Armas Químicas, existe uma ressalva ao uso de compostos químicos referidos nas respectivas listas com fins não proibidos pela Convenção sobre a Proibição do Desenvolvimento, Produção, Armazenagem e Utilização de Armas Químicas e sobre a Sua Destruição quando se destinem a "actividades industriais, agrícolas, de investigação, médicas, farmacêuticas ou outras realizadas com fins pacíficos" (i) da alínea I) do Artigo $3^{\circ}$ ).

Esperando que este problema seja merecedor da atenção de V. Ex. ${ }^{a}$, a Sociedade Portuguesa de Química fica ao dispor para contribuir para a solução do mesmo.

Com os meus melhores cumprimentos,

Paulo Ribeiro Claro

Secretário-Geral da SPQ 